\title{
Comparison of backstepping, sliding mode and PID regulators for a voltage inverter
}

\author{
Radouane Majdoul ${ }^{1}$, Abelwahed Touati ${ }^{1}$, Abderrahmane Ouchatti ${ }^{2}$, \\ Abderrahim Taouni ${ }^{2}$, Elhassane Abdelmounim ${ }^{3}$ \\ ${ }^{1}$ Laboratory of Complex Cyber Physical Systems in ENSAM, Hassan $2^{\text {nd }}$ University Casablanca, Casablanca, Morocco \\ ${ }^{2}$ Laboratory of Electrical Systems and Control Engineering at Aïn Chock Science Faculty, \\ Hassan $2^{\text {nd }}$ University Casablanca, Casablanca, Morocco \\ ${ }^{3}$ Laboratory of System Analysis and Information Technology in Science and Technical Faculty, \\ Hassan $1^{\text {st }}$ University Settat, Settat, Morocco
}

\section{Article Info \\ Article history: \\ Received Feb 2, 2021 \\ Revised Jul 20, 2021 \\ Accepted Aug 5, 2021 \\ Keywords: \\ Averaging model \\ Backstepping \\ DC-AC converter \\ Lyapunov \\ Nonlinear control \\ Sliding mode \\ Voltage inverter}

\begin{abstract}
In the present paper, an efficient and performant nonlinear regulator is designed for the control of the pulse width modulation (PWM) voltage inverter that can be used in a standalone photovoltaic microgrid. The main objective of our control is to produce a sinusoidal voltage output signal with amplitude and frequency that are fixed by the reference signal for different loads including linear or nonlinear types. A comparative performance study of controllers based on linear and non-linear techniques such as backstepping, sliding mode, and proportional integral derivative (PID) is developed to ensure the best choice among these three types of controllers. The performance of the system is investigated and compared under various operating conditions by simulations in the MATLAB/Simulink environment to demonstrate the effectiveness of the control methods. Our investigation shows that the backstepping controller can give better performance than the sliding mode and PID controllers. The accuracy and efficiency of the proposed backstepping controller are verified experimentally in terms of tracking objectives.
\end{abstract}

This is an open access article under the CC BY-SA license.

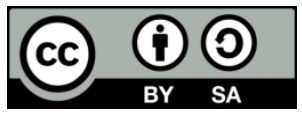

\section{Corresponding Author:}

Radouane Majdoul

Laboratory of Complex Cyber Physical Systems, ENSAM, Hassan $2^{\text {nd }}$ University of Casablanca

150, Nil Street, Sidi Othmane Casablanca, Morocco

Email: Radouane.majdoul@univh2c.ma

\section{INTRODUCTION}

In the literature, a multitude of types of controllers is developed and used to control the static power converters used in several electric systems (stand-alone or grid-connected photovoltaic systems, variable frequency drive, UPS...). Nowadays, system control is one of the richest domains in terms of algorithms, analysis tools, and design techniques. For a large class of non-linear systems, linear analysis methods generally give acceptable results. Classical linear methods are still used by many researchers [1]-[4] and others have designed their control strategy based on simple proportional integral (PI) or proportional resonant (PR) controllers [5], [6]. In some cases, approximate methods (the harmonic equivalent or Lyapunov's first method) are used to overcome the limitations of linear methods. Unfortunately for a large majority of systems, these two approaches remain insufficient and only provide the necessary conditions of stability. In other laboratories, researchers have shown interest in control strategies using the concept of platitude of differential systems [7]. This last technique allows state trajectories to be controlled even during a steady state. This property is not always ensured with PI controllers or other linear controllers. In other advanced 
control research works, we find interesting studies of comparative performance between different types of approaches: proportional integral derivative (PID) and fuzzy logic controllers or between sliding mode and platitude controllers [8], [9].

One of the most interesting approaches in recent years in the control and command of systems is the one based on Lyapunov's theory (second method) which presents a better alternative to linear methods [10]. The main idea of the use of the Lyapunov function (in adaptive control) is to compute a control law (and possibly a parameter updating law) to ensure that the derivative of a certain well-chosen positive defined function is non-positive. In his research, Houari [7] explored the platitude control strategy for the control of autonomous PV systems; this technique produces good results as a low response time of the order of $6 \mathrm{~ms}$ and a low total harmonic distortion (THD). A comparative analysis with a conventional type control (PID) and an advanced control using input-output linearization was proposed and justified the interest of the platitude control technique. More advanced methods based on Lyapunov theory such as backstepping, sliding mode, or passivity are still little used. In this paper, we propose the implementation of a single-phase voltage inverter used in a stand-alone photovoltaic system and controlled by a high-performance nonlinear controller. To ensure the best choice between three types of controllers, we establish a performance comparison between two non-linear controllers based on the Lyapunov function, namely the backstepping and the sliding mode controllers. This comparison also includes the performance of the system driven by the commonly used linear PID controller. These three controllers will be tested first in the presence of a sudden variation of the reference and then during a strong disturbance and large variation of the load. We make a comparison between the aforementioned controllers to justify the advantages and disadvantages of each one.

The remainder of this article is organized as follows: In section 2, a summary description is made of the pulse width modulation (PWM) inverter with an output LC filter. An equivalent mathematical model is presented using the theory of averaging values. Section 3 presents the development of three regulators types for this DC-AC converter system. The backstepping technique is developed first and, the sliding mode approach is the second case. Finally, we synthesized a PID controller to complete the comparison. The three controllers are tested, simulated, and implemented in the fourth section with comments and conclusions.

\section{MODELLING OF THE PWM VOLTAGE INVERTER AND THE LC OUTPUT FILTER}

\subsection{Mathematical model of the PWM inverter associated with the $L C$ filter}

The mathematical equations that govern the circuit in Figure 1 are noted in (1), (2):

$$
\begin{aligned}
& L \frac{d i_{L}}{d t}=v_{A B}-v_{S}-r \cdot i_{L} \\
& C \frac{d v_{S}}{d t}=i_{L}-i_{S}
\end{aligned}
$$

The output voltage $v_{A B}$ of the converter takes two bipolar levels according to the control signal $\mu$ and then to the state of the 4 power switches:

$$
\begin{aligned}
& v_{A B}=\left\{\begin{array}{rr}
V_{D C} & \text { when only }\left(K_{1}, K^{\prime}{ }_{2}\right) \text { are } O N \text { ie } \mu=1 \\
-V_{D C} & \text { when only }\left(K_{2}, K^{\prime}{ }_{1}\right) \text { are } O N \text { ie } \mu=-1
\end{array}\right. \\
& v_{A B}=\mu . V_{D C}
\end{aligned}
$$

We deduce the voltage expression $v_{A B}$ and subsequently the commuted model of the system.

$$
\begin{aligned}
& L \frac{d i_{L}}{d t}=\mu \cdot V_{D C}-v_{S}-r \cdot i_{L} \\
& C \frac{d v_{S}}{d t}=i_{L}-i_{S}
\end{aligned}
$$

Our DC-AC converter is a variable structure system. The signal $v_{A B}$ is not a continuous electrical quantity and takes two voltage levels $\mathrm{V}_{\mathrm{DC}}$ or $-\mathrm{V}_{\mathrm{DC}}$ so is unsuited for designing a continuous control law. The average model is widely used for modeling static converters [11], [12]; it assumes that the switching period is very small compared to the system dynamics. In our case, this is largely justified. Thus, the average model result of the inverter system is as (6), (7):

$$
C \dot{x}_{1}=x_{2}-i_{S}
$$




$$
L \dot{x}_{2}=u \cdot V_{D C}-x_{1}-r \cdot x_{2}
$$

where $x_{1}$ and $x_{2}$ respectively denote the average values over the switching period of $v_{S}$ the voltage across the capacitor $\mathrm{C}$ and $i_{L}$ the current flowing in the inductor $\mathrm{L}$. The control system input $u$ takes continuous values between -1 and 1 and represents the mean value of the PWM control signal $\mu$. The electrical quantities $x_{I}$ and $x_{2}$ are accessible and measurable.

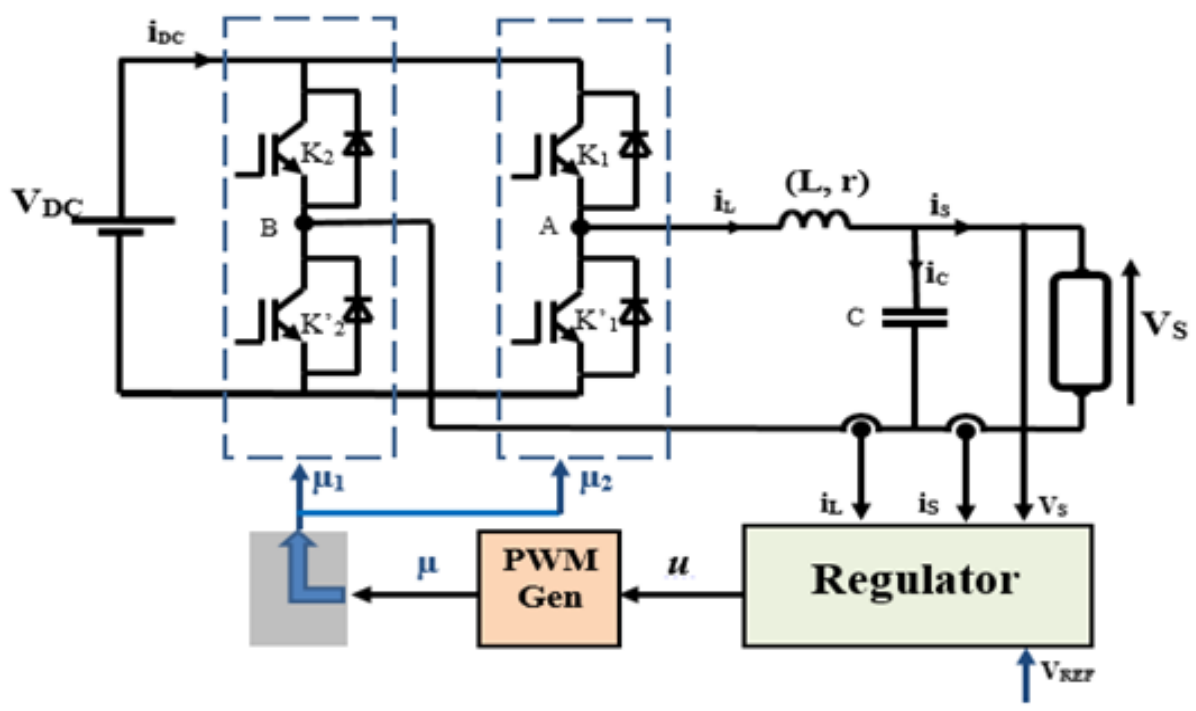

Figure 1. The single-phase PWM inverter associated with the output LC filter

\section{CONTROLLERS DESIGN}

Our objective is to design three controllers that allow the inverter to produce a pure sine wave voltage with a fixed amplitude and frequency regardless of the load. The output voltage must track a desired reference signal:

$$
x_{1}^{d}(t)=V \sqrt{2} \sin (\omega t)
$$

$V=230 \mathrm{~V}$ and $\omega=2 \pi 50$ represent respectively, the RMS and the frequency of the sinusoidal reference signal.

\subsection{Design of backstepping controller}

In control theory, the backstepping approach has been developed to design stabilized controls for nonlinear dynamic systems [13], [14]. In this approach, control systems are designed and developed from basic subsystems radiating from an unreducible one that can be stabilized using other techniques. Due to the recursive design structure, the developer is able to begin the design process at the known-stable system and back out new controls that gradually stabilize each outer subsystem. The process ends after many steps when the final outer control is achieved. Therefore, this process is commonly known as "backstepping control" [15]-[19].

Step 1: Design of the inner loop

Consider the tracking error $\mathrm{z}_{1}$ defined by (8):

$$
z_{1}=C\left(x_{1}-x_{1}^{d}\right)
$$

Its dynamics is given by (9), (10):

$$
\begin{aligned}
& \dot{z}_{1}=C\left(\dot{x}_{1}-\dot{x}_{1}^{d}\right) \\
& \dot{z}_{1}=x_{2}-i_{S}-C \dot{x}_{1}^{d}
\end{aligned}
$$

Let's use the Lyapunov candidate function: 


$$
V_{1}=\frac{1}{2} z_{1}^{2}
$$

As its derivative with respect to time, is given by (12):

$$
\dot{V}_{1}=\dot{z}_{1} z_{1}
$$

The choice,

$$
\dot{z}_{1}=-k_{1} z_{1}
$$

where $\mathrm{k}_{1}$ is a positive constant which leads to a Lyapunov candidate function with negative dynamics. One obtains therefore;

$$
\dot{V}_{1}=-k_{1} z_{1}^{2}
$$

Therefore asymptotic stability of the sub-system (10) is reached and $\mathrm{z}_{1}$ is exponentially tending towards 0 . In this subsystem, $x_{2}$ is assimilated to a virtual control input. So $z_{1}$ can be adjusted to zero if: $x_{2}=x_{2}^{d}$.

$$
x_{2}^{d}=-k_{1} z_{1}+i_{S}+C \dot{x}_{1}^{d}
$$

Where $x_{2}^{d}$ called the stabilizing function. A new variable error between virtual control and its desired value is defined as (16)

$$
z_{2}=x_{2}-x_{2}^{d}
$$

It can be deduced from (10), (15) and (16) the new dynamic expression of the tracking error:

$$
\dot{z}_{1}=-k_{1} z_{1}+z_{2}
$$

Step 2: Voltage outer loop design

The dynamic of $\mathrm{z}_{2}$ is calculated as (18):

$$
\begin{aligned}
& \dot{z}_{2}=\dot{x}_{2}-\dot{x}_{2}^{d} \\
& \dot{z}_{2}=\frac{1}{L}\left(u \cdot V_{D C}-x_{1}-r \cdot x_{2}\right)-\dot{x}_{2}^{d}
\end{aligned}
$$

The real control system appears in (19). The stabilization problem of the system depicted by (17) and (19) can be expressed by the new Lyapunov function:

$$
\begin{aligned}
& V_{2}=\frac{1}{2} z_{1}^{2}+\frac{1}{2} z_{2}^{2} \\
& \dot{V}_{2}=\dot{z}_{1} z_{1}+\dot{z}_{2} z_{2} \\
& \dot{V}_{2}=-k_{1} z_{1}^{2}+z_{2}\left(z_{1}+\dot{z}_{2}\right)
\end{aligned}
$$

By imposing in the (23):

$$
\left(z_{1}+\dot{z}_{2}\right)=-k_{2} z_{2}
$$

We obtain,

$$
\dot{V}_{2}=-k_{1} z_{1}^{2}-k_{2} z_{2}^{2} \quad<0
$$

So, the (19) and (23) are the basis for the development of the backstepping controller algorithm:

$$
u=-\frac{L}{V_{D C}}\left(z_{1}+k_{2} z_{2}-\frac{x_{1}+r \cdot x_{2}}{L}-\dot{x}_{2}^{d}\right)
$$


We deduce the asymptotic stability in the origin of the error system (10)-(19). This results the closed-loop stability of the controlled system (3) and the regulation to zero of the tracking error. The system $\left(z_{1}, z_{2}\right)$ is thus globally asymptotically stable.

$$
\left(\begin{array}{l}
\dot{z}_{1} \\
\dot{z}_{2}
\end{array}\right)=\left(\begin{array}{cc}
-k_{1} & 1 \\
-1 & -k_{2}
\end{array}\right)\left(\begin{array}{l}
z_{1} \\
z_{2}
\end{array}\right)
$$

Where $\left(k_{1}, k_{2}\right)$ are positive real constants of synthesis. The control law chosen so that $\dot{V}_{2}<0$ allows the closed-loop system to be globally asymptotically stable. More precisely, its dynamics is described in $\left(\mathbf{z}_{1}, z_{2}\right)$ coordinates defined by the expression (26).

\subsection{Sliding mode controller design}

In control theory, sliding mode control (SMC) is a nonlinear control method that changes the dynamics of the system to be controlled by applying a discontinuous control signal that forces the system to "slide" along a cross-sectional area of normal system behavior and remain there until equilibrium. The control law is not a continuous function of time. It is a variable-structured control that can change its structure and switch between two values according to a very specific switching logic [20].

One main application of sliding mode controllers is the control of electrical drives operated by static power converters; a lot of research work has been devoted to this [21]-[24]. The synthesis of the sliding mode control is done in three steps: i) choice of the sliding surface, ii) establishing the convergence condition, and iii) determining the control law that allows reaching and staying on the surface. The choice of the sliding surface is determined based on the system and the desired performance. Our main control objective is always the same: the designed control must still allow the inverter to deliver a pure sine wave voltage with a fixed amplitude and frequency, independently of the load. The output voltage must match a reference signal:

$$
x_{1}^{d}(t)=V \sqrt{2} \sin (\omega t)
$$

Considering the same tracking error $\mathrm{z}$ and its dynamics is given by the following expressions:

$$
\begin{aligned}
& z=C\left(x_{1}-x_{1}^{d}\right) \\
& \dot{z}=C\left(\dot{x}_{1}-\dot{x}_{1}^{d}\right) \\
& \dot{z}=x_{2}-i_{S}-C \dot{x}_{1}^{d} \\
& \ddot{z}=\frac{1}{L}\left(u \cdot V_{D C}-x_{1}-r \cdot x_{2}\right)-\frac{d i_{S}}{d t}-C \ddot{x}_{1}^{d}
\end{aligned}
$$

The sliding function is defined as (31):

$$
S(x)=k z+\frac{d z}{d t}
$$

The dynamics of this sliding function is (32):

$$
\dot{S}(x)=k \frac{d z}{d t}+\frac{d^{2} z}{d t^{2}}
$$

Using (29), (30) and (32), we obtain:

$$
\dot{S}(x)=k\left(x_{2}-i_{S}-C \dot{x}_{1}^{d}\right)+\frac{1}{L}\left(u E-x_{1}-r \cdot x_{2}\right)-\frac{d i_{S}}{d t}-C \ddot{x}_{1}^{d}
$$

To guarantee the convergence of the sliding surface in a finite time, the following Lyapunov candidate function is defined:

$$
\begin{aligned}
& V_{1}=\frac{1}{2} S^{2} \\
& \dot{V}_{1}=\dot{S} S
\end{aligned}
$$


To ensure that the derivative of the Lyapunov function is negative, we take the following expression:

$$
\dot{S}=-\beta \operatorname{sgn}(S)
$$

where $\operatorname{sgn}(S)=1$ when $S>0$ or -1 when $S<0$ and $\beta$ positive constant of synthesis.

We obtain the novel expression of the Lyapunov function dynamics:

$$
\dot{V}_{1}=-\beta .|S|<0
$$

Using (33) and (34), we deduce

$$
u=\frac{x_{1}+r \cdot x_{2}}{V_{D C}}+\frac{L}{V_{D C}}\left(-\beta \operatorname{sgn}(S)-k\left(x_{2}-i_{S}-C \dot{x}_{1}^{d}\right)\right)+\frac{L}{V_{D C}}\left(\frac{d i_{S}}{d t}+C \ddot{x}_{1}^{d}\right)
$$

\subsection{Design of the PID controller}

The PI and PID controllers are widely used in the industry since historically simple analog techniques have been used for their realization. Currently, despite the predominance of the digital approach, PI and PID are still used in many applications as they are robust and do not presuppose a precise knowledge of the dynamics and model of the process to be controlled [25]. To set the PID parameters, several generations of industrial automations are often satisfied with a screwdriver for any theory.

There are many different approaches to define the PID parameters in the specialized literature. The method that we recommend here is an algebraically approach based on the knowledge of the global system model (PWM Inverter, LC filter, and the load). The PID parameters are chosen to compensate the two poles of the system and to tune its dynamics in the closed loop. We propose to model the PWM inverter associated to the LC filter by the block diagram shown in Figures 2(a) and 2(b).

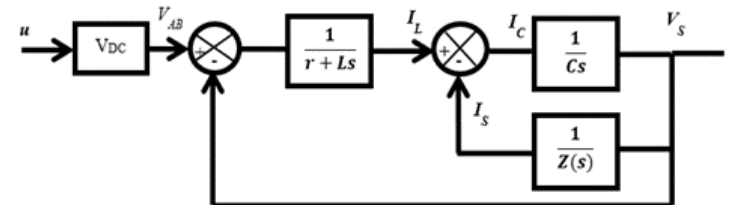

(a)

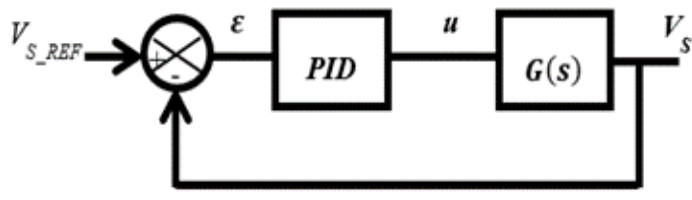

(b)

Figure 2. Schematics; (a) block diagram modeling the system to be controlled, (b) system control loop with PID controller

The transfer function of the association of PWM inverter and LC filter is given by (37):

$$
G(s)=\frac{V_{D C}}{1+\frac{r}{R}+\left(\frac{L}{R}+r C\right) s+L C s^{2}} \approx \frac{V_{D C}}{1+\frac{L}{R} s+L C s^{2}}
$$

The PID controller produces the signal control $u(t)$ from the error $\varepsilon(\mathrm{t})$ according to $(38)$ :

$$
u(t)=K_{P}\left[\varepsilon(t)+\frac{1}{T_{i}} \int_{0}^{t} \varepsilon(t) d t+T_{d} \frac{d \varepsilon(t)}{d t}\right]
$$

His expression transmittance of Laplace:

$$
\frac{U(s)}{\varepsilon(s)}=\frac{K_{P}}{E} \cdot\left[1+\frac{1}{T_{i} \cdot s}+T_{d \cdot s}\right]
$$

Which can be written in the other way:

$$
\frac{U(s)}{\varepsilon(s)}=K_{P}^{\prime} \cdot\left[\frac{1+T_{i} \cdot s+T_{i} \cdot T_{d} \cdot s^{2}}{T_{i} \cdot s}\right]
$$

The parameters $T_{i}$ and $T_{d}$ are defined to compensate the two poles of the system, the proportional parameter to adjust the dynamic of the controlled systems: 


$$
T_{i}=\frac{L}{R} ; \quad T_{d}=R \cdot C ; \quad T_{0}=\frac{L}{R \cdot K^{\prime} P}
$$

The transfer function of the closed loop becomes:

$$
F(s)=\frac{1}{1+T_{0} s}
$$

\section{PERFORMANCE COMPARATIVE AND SIMULATIONS RESULTS}

\subsection{Simulation conditions overview}

In this part, we implement the circuit of the bridge voltage inverter associated with the LC filter in the MATLAB/Simulink environment. Then we test the performance of the system controlled by each of the three previously designed regulators in order to establish a comparative study. For this purpose, we evaluate the performance of the regulators during a strong and abrupt variation of the reference signal and during a strong perturbation of the output current. To test the tracking, the output voltage must track a sine wave reference, which suddenly increases from $115 \mathrm{~V}$ to $230 \mathrm{~V}$ RMS. The second simulation test involves the controllers' response to a perturbation provoked by a strong increment of the output current from 23 A to 46 A RMS. Table 1 summarizes all the simulation parameters considered for the system and the controllers.

Table 1. Simulation system parameters

\begin{tabular}{ccc}
\hline Parameter designation & Symbols & Numerical values \\
\hline Voltage DC bus & $\mathrm{V}_{\mathrm{DC}}$ & $600 \mathrm{~V}$ \\
Output filter & $\mathrm{L}$ & $2 \mathrm{mH}$ \\
& $\mathrm{C}$ & $50 \mu \mathrm{F}$ \\
Load & $\mathrm{r}$ & $10 \mathrm{~m} \Omega$ \\
Reference signal & $\mathrm{R}$ & $10 \Omega$ \\
& $\mathrm{V}_{\mathrm{REF}}$ & $230 \mathrm{~V}$ \\
& $\omega$ & $100 \pi$ \\
Backstepping controller parameters & $\mathrm{K}_{1}$ & 4000 \\
& $\mathrm{~K}_{2}$ & 4000 \\
Sliding mode controller parameters & $\beta$ & 60000 \\
& $\mathrm{~K}$ & 8000 \\
PID parameter & $\mathrm{T}_{0}$ & $0.001 \mathrm{~s}$ \\
\hline
\end{tabular}

\subsection{Evaluation of performances during the pursuit}

Figure 3 presents the results of the system simulation where the reference voltage is tracked. In Figure 3(a), we present the output voltage and the reference voltage respectively for each of the three control types: Backstepping, sliding mode and the PID controllers. In Figure 4(a), the output voltage perfectly tracks the reference and converges rapidly even when the reference suddenly undergoes a large variation: the RMS value of the reference changes from $115 \mathrm{~V}$ to $230 \mathrm{~V}$. The controllers' backstepping and sliding mode response time $(\approx 1 \mathrm{~ms})$ is very small and very interesting compared to that of the PID. The PID takes more time $(\approx 6 \mathrm{~ms})$ for the output voltage to converge to the reference. In Figure 3(b), we show the shape of the control signal provided during tracking by each of the three types of controllers. We notice that the control of the sliding mode controller is much harsher than that of the backstepping. It is possible to make it softer but the response time will increase consequently. On the other hand, the PID reacts intensely when the reference is changed and its control becomes very hard during the time needed for the output voltage to converge to the new reference.

\subsection{Evaluation of performances during regulation and compensation of a large load variations}

In this section, we consider the simulation results of the system and the variations of its electrical quantities when applying a power step represented by a strong and sudden increase of the output current. In Figures 4(a) and 4(b), we present in the same way the output voltage, reference voltage and control signal waveforms respectively for the three types of regulators. The PID regulator responds correctly during this strong disturbance, the output voltage converges quickly to the reference with small oscillations. However, its control is very severe when applying the power step and takes a quarter of a period to become smoother again. The responses of the backstepping and sliding mode regulators are very good, the output voltage drops but quickly converges to the reference after the output current suddenly increases. The sliding mode regulator always produces a very harsh control compared to the backstepping controller. 

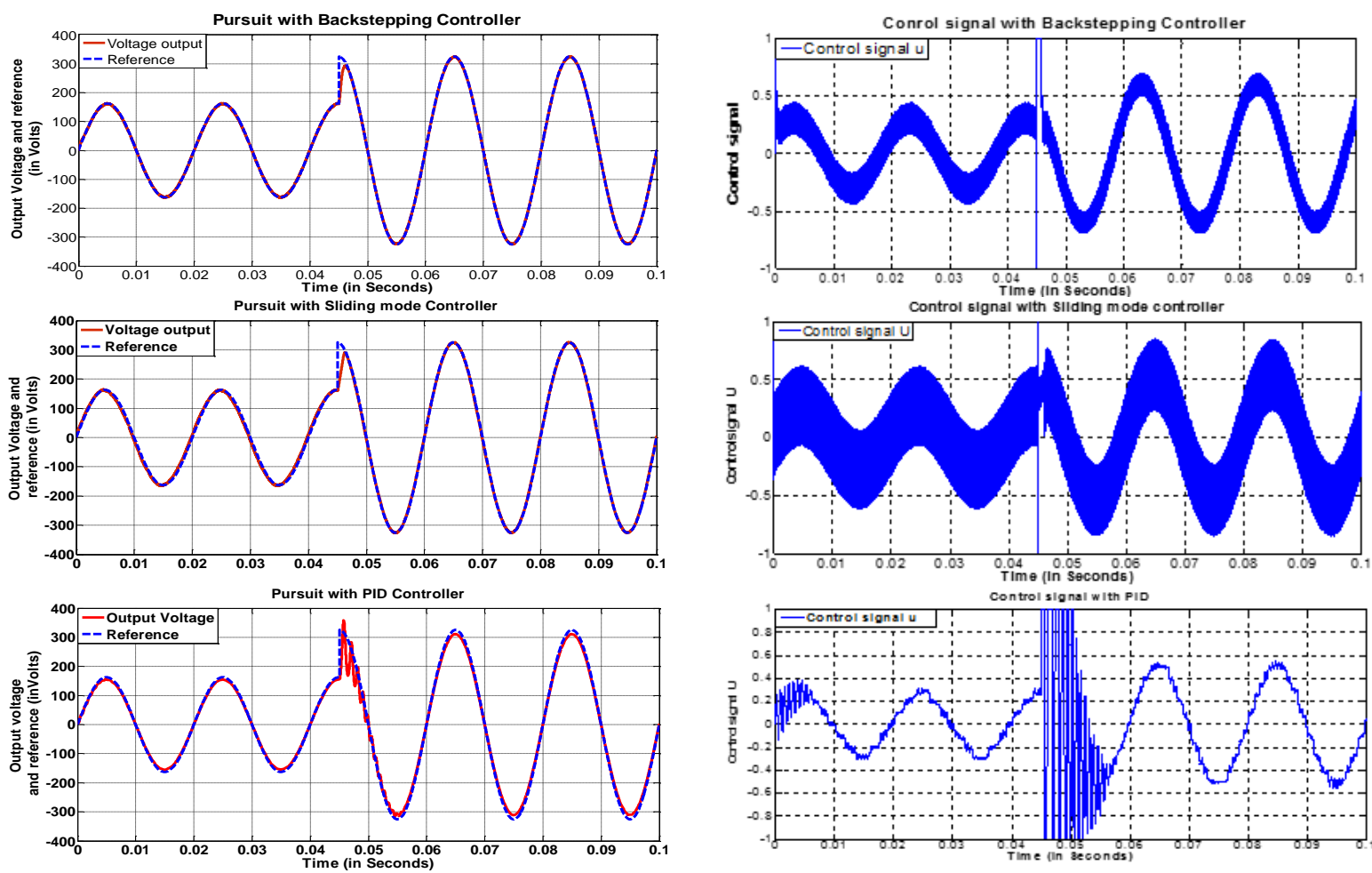

(a)

(b)

Figure 3. Comparison of the performance of the three controllers during tracking and large reference variation; (a) shapes of output and reference voltages, (b) control signal
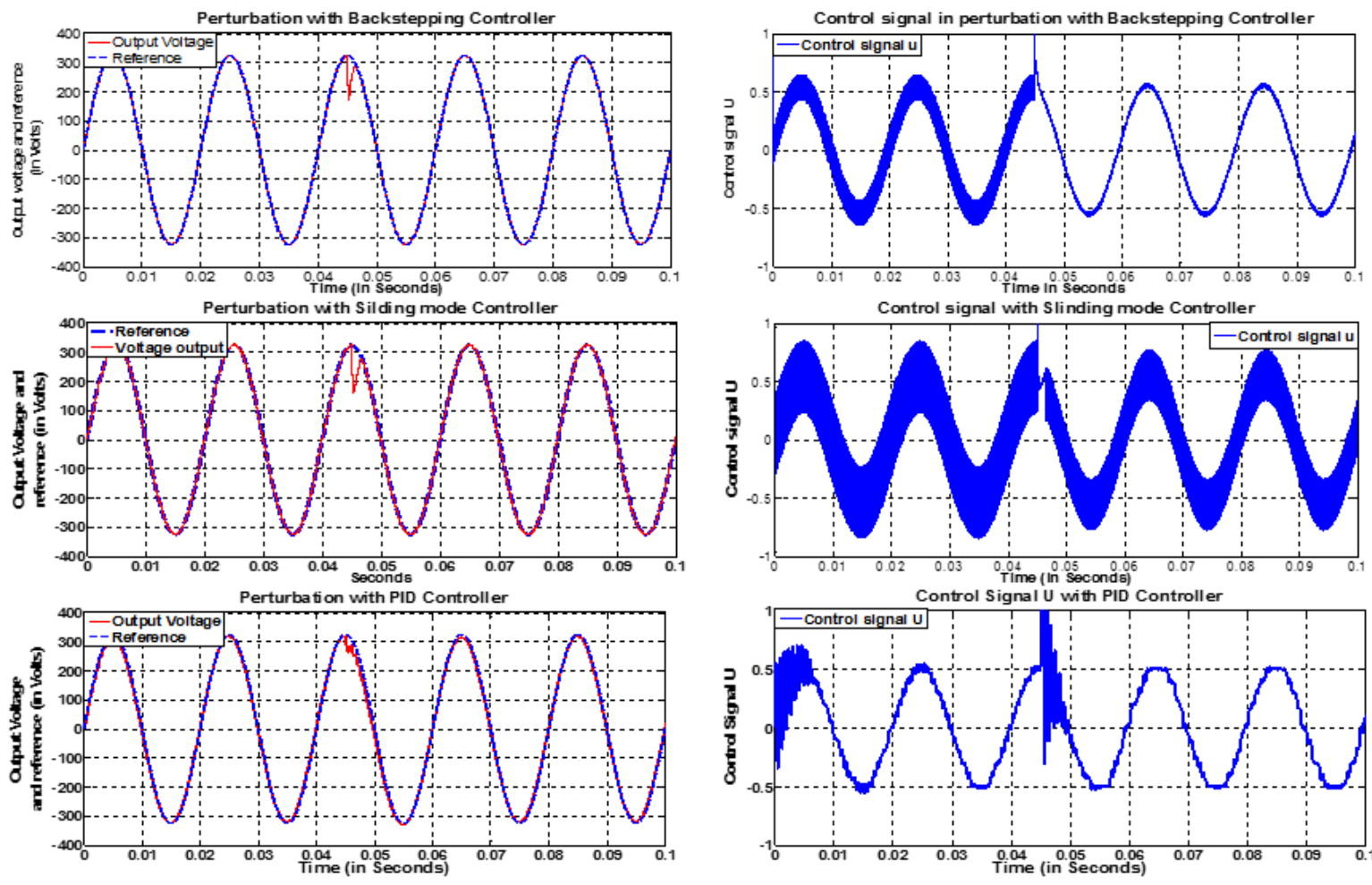

(a)

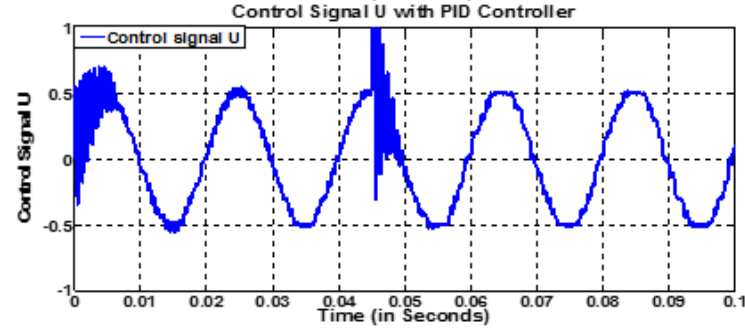

(b)

Figure 4. Comparison of the three controllers during a high power step and a high output current disturbance; (a) shapes of output and reference voltages, (b) control signal 


\subsection{Practical achievements and experimental validation of the backstepping regulator}

The final step in this proposal is to implement the backstepping controller in a real system. In this context, we are led to design and build a voltage inverter that can operate in single-phase or three-phase. For a compact solution of the power inverter that is easy to interface with the control and instrumentation electronics, we opted for the use of a high-performance intelligent power module (PSS35S92F6-AG from Mitsubishi). The choice of this IPM is justified by many properties: Fast 7th generation IGBTs of the $450 \mathrm{~V}-35 \mathrm{~A}$ class, use of a single $15 \mathrm{~V}$ voltage source for control by integrating the level shift of the control voltage of the high stage transistors using a circuit of resistors and bootstrap diodes, integrated active overcurrent, and overload protection and finally, the control inputs are compatible with 3.3 and $5 \mathrm{~V}$ microcontroller voltage levels. The control scheme is implemented in a DSP module eZdsp F28335 which generates the gating signals (ePWM A, ePWM B) and dead times for the device.

Due to hardware limitations, only the pursuit test is performed in the experiment and the actual values for the output filter has been increased to $L=76 \mathrm{mH} \& \mathrm{C}=60 \mu \mathrm{F}$. As depicted in Figure 5, the experimental bench realized is also composed of a DSP smart card and measurement and conditioning cards. Figure 6 shows the blocks for calibrating and levelling the digitalized quantities of the measured voltages and currents. The offset blocks make the digitized data bipolar between -2048 and 2047 for the alternating quantities. The gain blocks are designed so that the maximum values of the quantities to be measured correspond to 2047 for the alternating quantities and 4095 for the unipolar quantities.
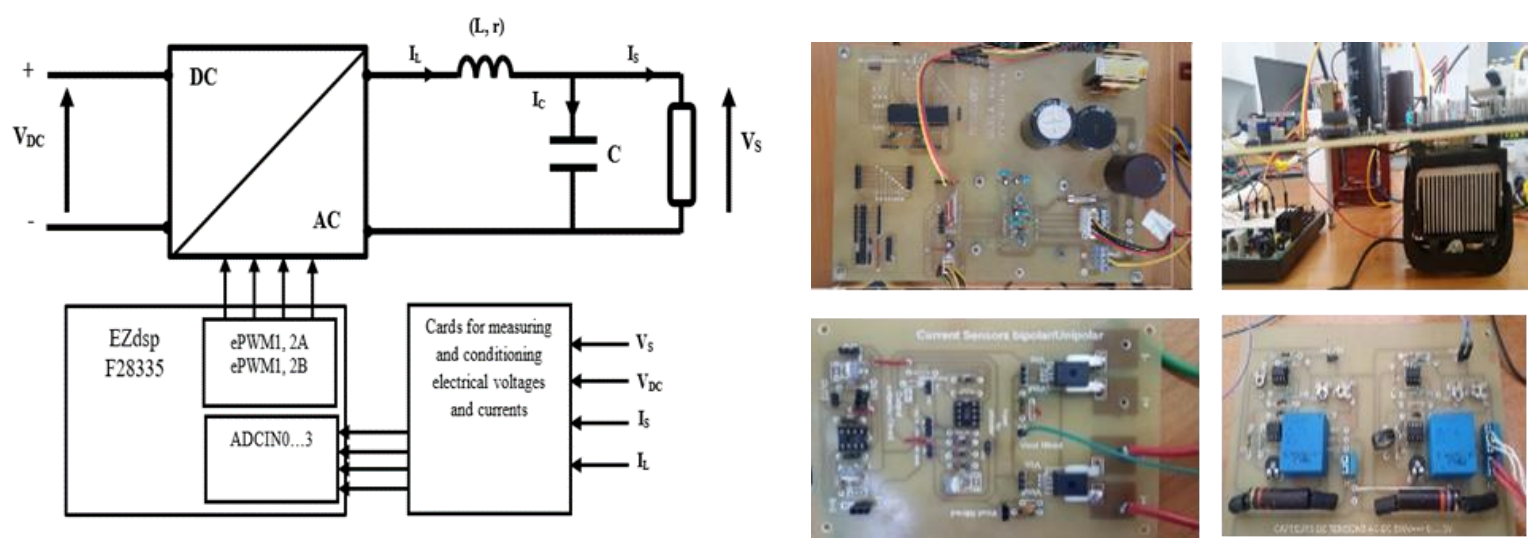

Figure 5. Single-phase bridge inverter circuit driven by the DSP board eZdsp F28335 implementing the backstepping regulator, the acquisition module and the ePWM module. Voltages and currents are measured with galvanic isolation using LV-25P and ACS758B Hall Effect sensors

For the control and monitoring of static power converters, The TI's card has 6 ePWM devices with two outputs (ePWMAx and ePWMBx) that can operate independently or in a complementary manner (to control the semiconductor switches of the same inverter arm). For the generation of PWM commands, we specify for each ePWM channel its time base and the hash rate value in the 16-bit TBPRD register. This value depends on the frequency of the system clock, on the TBPRD counting mode (Up, Down or Up/Down) and on a pre-divider coefficient (Prescaler) allowing to bring this value between 0 and 65535 .

$$
\text { Timer }_{\text {period }}=\frac{F_{S Y S}}{\text { Prescaler. } F_{P W M} \cdot k}=\frac{150 e 6}{1.20 e 3.2}=3750
$$

To control the inverter, the command signal u generated by the backstepping controller is bipolar and is between -1 and 1 . A digital adaptation stage between $u$ and $\alpha$ is required.

$$
\alpha=\frac{1+u}{2}=\frac{C M P A}{3750} \Rightarrow C M P A=3750 *\left(\frac{1+u}{2}\right)=1875+1875 * u
$$

In the Simulink environment, we implement the backstepping controller algorithm, the acquisition module and the ePWM module as shown in Figure 6. The complete set is converted into C language and then transferred to the eZdsp F28335 board using the Code Composer Studio which is an integrated development environment for the programming of embedded processors from Texas Instruments of the TMS320 family. 
The system is tested for sinusoidal references with frequency $50 \mathrm{~Hz}$ and with two RMS values: for $55 \mathrm{~V}$ RMS, the results are shown in Figures 7(a) and 7(b), and the results for $110 \mathrm{~V}$ RMS are shown in Figures 8(a) and 8(b). The waveforms obtained allows us to confirm the correct performance of the proposed backstepping controller. The response of the drive is very close to the simulation results. Note that, the high quality of voltage output filter is obtained using high switching frequency and an oversized LC filter which, due to its low-pass nature, eliminates high-frequency switching harmonics.

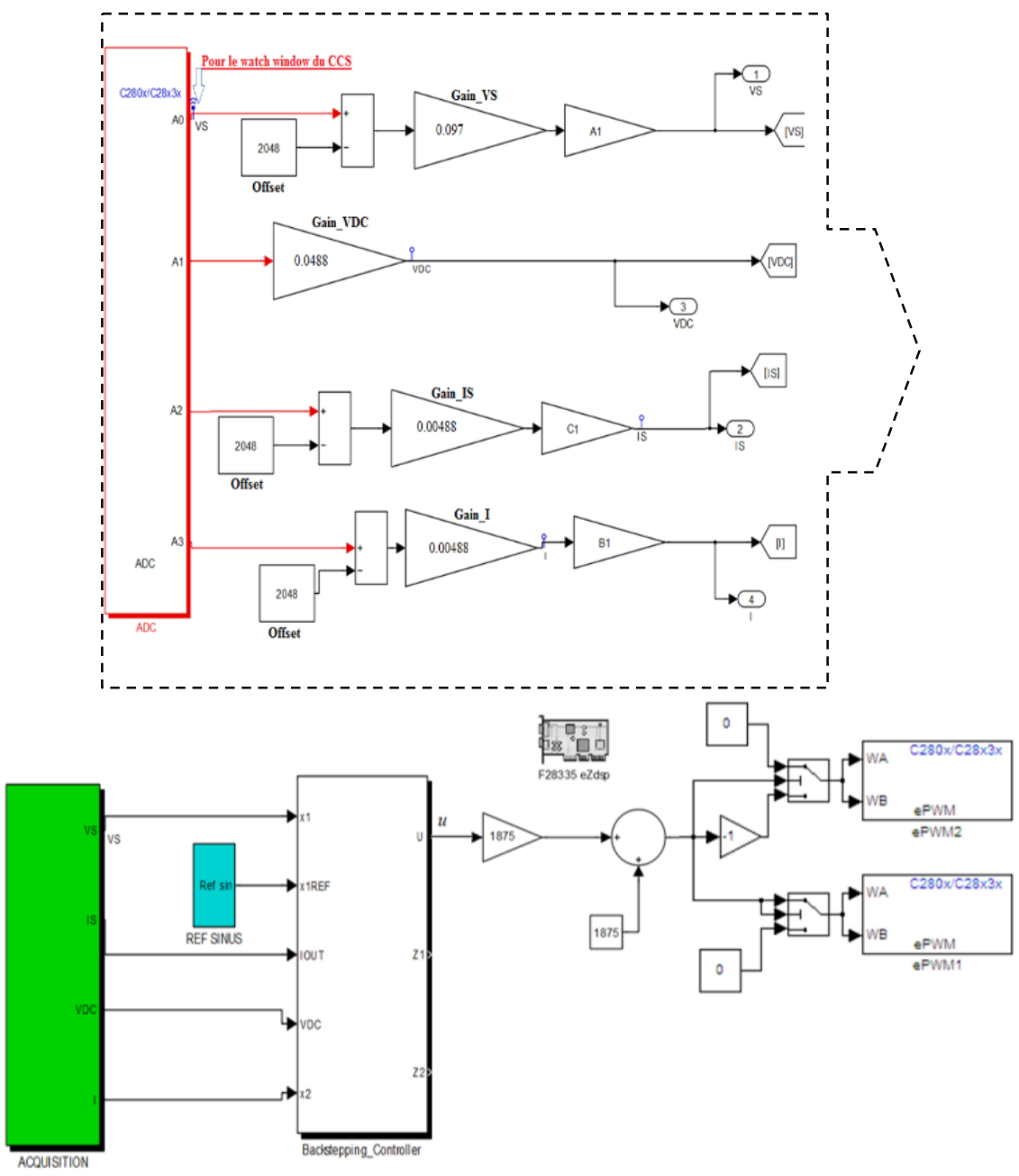

Figure 6. Implementation in the Simulink environment (with eZdsp libraries) of the acquisition module, the backstepping controller and the ePWM module for unipolar control of the single-phase inverter

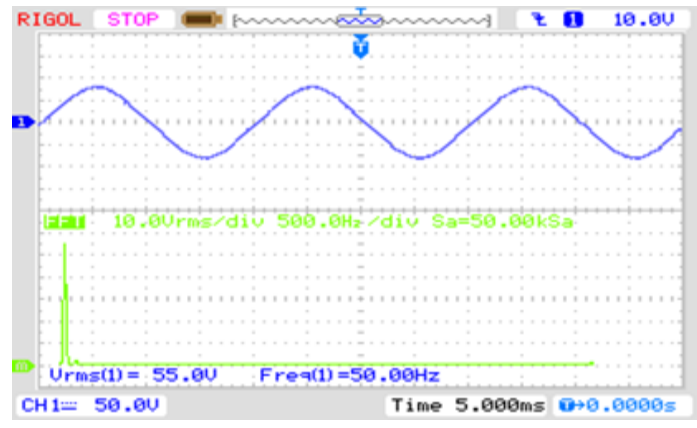

(a)

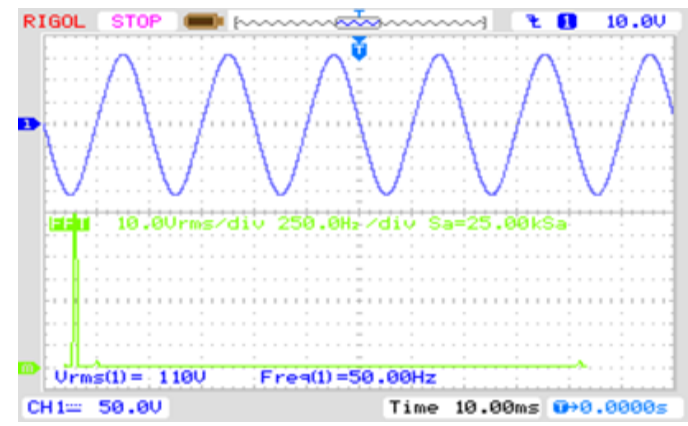

(b)

Figure 7. Output voltage signal and its FFT for sine reference voltages at $50 \mathrm{~Hz}$; (a) $55 \mathrm{~V} \mathrm{RMS}$, (b) $110 \mathrm{~V}$ RMS 


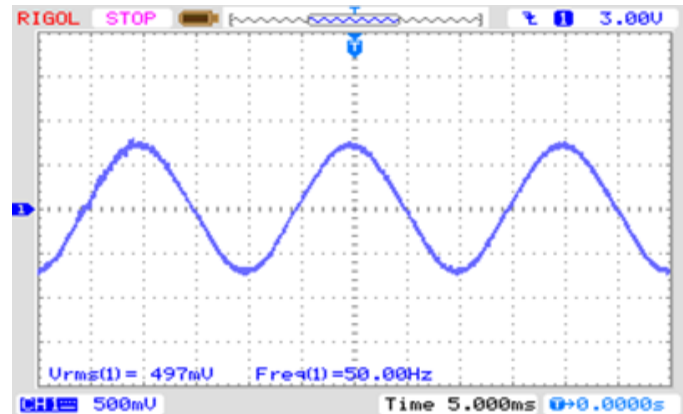

(a)

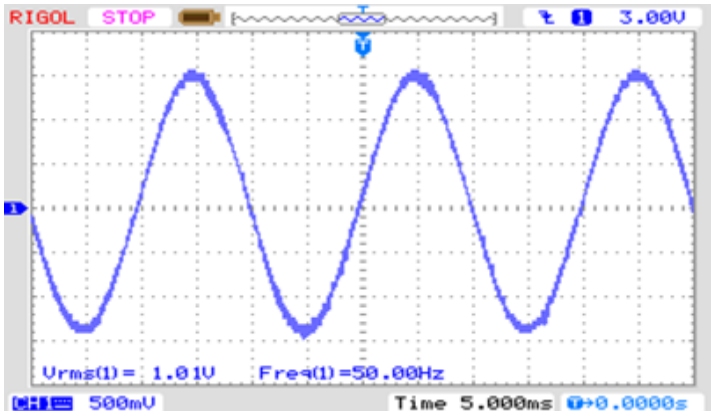

(b)

Figure 8. Output current signal for sine reference voltages at $50 \mathrm{~Hz}$; (a) $55 \mathrm{~V}$ RMS, (b) $110 \mathrm{~V}$ RMS

\section{CONCLUSION}

In this paper, we are interested in the study of the controller synthesis for DC-AC power converters. Our purpose was twofold: i) to design, using three different approaches, a control law that stabilizes the system, ensures good tracking of the output voltage of a sinusoidal reference variable, and provides correct regulation in the presence of a large load variation; ii) to establish a comparative performance analysis of three controllers: Backstepping, sliding mode, and PID, in order to determine which choice provides the best performance. The simulation results show that the three controllers designed allow a good tracking and a good regulation of the output voltage. However, it should be noted that it is the backstepping controller that offers better performance: low response time and smoother control. The sliding mode regulator is also powerful and fast, but unfortunately, its control is very harch. However, on the other hand, the PID has a longer response time than the other two controllers. Also when the load or reference varies, the current in the inductor is not controlled and may have a large overcurrent, which is another disadvantage for the PID. It is important to note that the backstepping controller, with its good performance, has certain constraints during its synthesis, which is done in several steps depending on the system to be controlled. Indeed, the ki synthesis constants are not calculated mathematically but are chosen in an approximate way, and are only validated after numerous tests and trials on the system. Further comparative studies between advanced adaptive backstepping variants, second-order sliding mode and passivity-based controllers may enhance this work.

\section{REFERENCES}

[1] C. Kalavalli, K. P. Kathirvelu, and R. Balasubramanian, "Single phase bidirectional PWM converter for microgrid system," International Journal of Engineering and Technology (IJET), vol. 5, no. 3, pp. 2436-2441, Jun.-Jul. 2013.

[2] L. Xiangli and Q. Hanhong, "One-cycle controlled single phase UPS inverter," ICSSDMS, Physics Procedia, vol. 25, pp. 1048-1054, 2012, doi: 10.1016/j.phpro.2012.03.198.

[3] Y. Yang and F. Blaabjerg, "Overview of single-phase grid-connected photovoltaic systems," Electric Power Components and Systems, vol. 43, no 12, pp. 1352-1363, 2015, doi: 10.1080/15325008.2015.1031296.

[4] D. Picault, "Reduction of mismatch losses in grid-connected photovoltaic systems using alternative topologies," Thesis presented in National Polytechnic Institut of Grenoble, France, 2010

[5] E. Tomaszewski and J. Jiangy, "An anti-windup scheme for proportional resonant controllers with tuneable phase-shift in voltage source converters," 2016 IEEE Power and Energy Society General Meeting (PESGM), Boston, MA, 2016, pp. 1-5, doi: 10.1109/PESGM.2016.7741367.

[6] A. A. Nazeri, P. Zacharias, F. M. Ibanez, and S. Somkun, "Design of proportional-resonant controller with zero steady-state error for a single-phase grid-connected voltage source inverter with an LCL output filter," 2019 IEEE Milan PowerTech, Milan, Italy, 2019, pp. 1-6, doi: 10.1109/PTC.2019.8810554.

[7] A. Houari, "Contribution to the study of autonomous micro-grids powered by photovoltaic sources," (in French), Thesis presented in National Higher School of Electricity and Mecanic of Nancy, France, 2010.

[8] I. Aidi, M. Ayadi, M. Benrejeb, P. Borne., "Comparative performance of sliding mode and platitude control methods of a motorized throttle valve," (in French), e-STA 2010-2, vol. 7, no. 2, pp. 1-8, 2010

[9] R. Bhatnagar, M. M. Anwer, and Manish, "Design and analytical comparison of various controllers used in PWM inverter," Internatonal Journal Research in Science Engineering and Technology (IJRSET), vol. 1, no. 3, pp. 07-012, 2012.

[10] A. Benaskeur, "Aspects of the application of adaptive backstepping to the decentralized control of nonlinear systems," (in French), Thesis in Laval University, Laval, Canada, 2000. [Online]. Available:
[ https://corpus.ulaval.ca/jspui/handle/20.500.11794/41020

[11] P. T. Krein, J. Bentsman, R. M. Bass, and B. L. Lesieutre, "On the use of averaging for analysis of power electronic system," IEEE Transaction on Power Electronics, vol. 5, no. 2, pp. 182-190, 1990, doi: 10.1109/63.53155.

[12] B. Lehman and R. M. Bass, "Switching frequency dependent averaged models for PWM DCDC converters," IEEE Transaction on Power Electronics, vol. 11, no. 1, pp. 89-98, 1996, doi: 10.1109/63.484421.

[13] M. Krstic, I. Kanellakopoulos, and P. V. Kokotovic, "Nonlinear design of adaptive controllers for linear systems," IEEE Transactions on Automatic Control, vol. 39, no. 4, pp. 738-752, 1994, doi: 10.1109/9.286250. 
[14] M. Krstic, I. Kanellakopoulos, and P. V. Kokotovic, "Nonlinear and adaptive control design,” John Willy \& Sons, NY, 1995

[15] R. Majdoul, A. Abouloifa, E. Abdelmounim, M. Aboulfatah, A. Touati, and A. Moutabir, "Backstepping controller of five-level three-phase inverter," MATEC Web of Conferences, EDP Sciences, vol. 16, May 2014, doi: 10.1051/matecconf/20141606003.

[16] Y. Fang, J. Fei, and T. Hu, "Adaptive backstepping fuzzy sliding mode vibration control of flexible structure," Journal of Low Frequency Noise, Vibration and Active Control, vol. 37, pp. 1079-1096, 2018, doi: 10.1177/1461348418767097.

[17] A. Taouni, A. Abbou, M. Akherraz, A. Ouchatti, and R. Majdoul, "MPPT design for system using backstepping control with boost converter," in International Renewable and Sustainable Energy Conference (IRSEC), Marrakech, Morocco, 2016, pp. 469-475, doi: 10.1109/IRSEC.2016.7983920.

[18] M. Arsalan, R. Iftikhar, I. Ahmad, A. Hasan, K. Sabahat, and A. Javeria, "MPPT for photovoltaic system using nonlinear backstepping controller with integral action," Solar Energy, vol. 170, pp. 192-200, 2018, doi: 10.1016/j.solener.2018.04.061.

[19] Y. Fang, J. Fei, and Y. Yang, "Adaptive backstepping design of a microgyroscope," Micromachines, vol. 9, no. 7, 2018, Art. no. 338, doi: 10.3390/mi9070338

[20] V. I. Utkin, "Sliding modes in control optimization," Communication and Control Engineering Series, Springer-Verlag Berlin Heidelberg, 1992, doi: 10.1007/978-3-642-84379-2.

[21] T. Abderrahim, T. Abdelwahed, and M. Radouane, "Improved strategy of an MPPT based on the sliding mode control for a PV system," International Journal of Electrical and Computer Engineering (IJECE), vol. 10, no. 3, pp. 3074-3085, Jun. 2020, doi: 10.11591/ijece.v10i3.pp3074-3085.

[22] Y. Zhu and J. Fei, "Disturbance observer based fuzzy sliding mode control of PV grid connected inverter," in IEEE Access, vol. 6, pp. 21202-21211, 2018, doi: 10.1109/ACCESS.2018.2825678.

[23] Y. Zhu and J. Fei, "Adaptive global fast terminal sliding mode control of grid-connected photovoltaic system using fuzzy neural network approach," in IEEE Access, vol. 5, pp. 9476-9484, 2017, doi: 10.1109/ACCESS.2017.2707668.

[24] T. Abdelwahed, M. Radouane, T. Abderrahim, M. Aboulfatah, and R. Nabila, "Comparative study between fast terminal and second order sliding mode controls applied to a wind energy conversion system," Indonesian Journal of Electrical Engineering and Computer Science (IJEECS), vol. 22, no. 2, pp. 157-171, May 2021, doi: 10.11591/ijeecs.v22.i2.pp765-779.

[25] K. J. Astrom and T. Hagglund, "PID controllers: Theory, design and tuning," Instrument Society of America, Research Triangle Park, NC., 1995.

\section{BIOGRAPHIES OF AUTHORS}

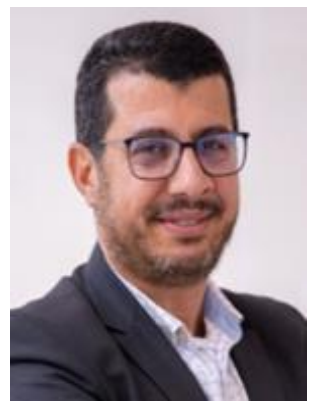

Radouane Majdoul (D) 8 SC P was born in Meknes, Morocco, in 1969. He received the Engineer degree in electrical Engineering from High Institute of Technical Education (ENSET) of Rabat in 1991. In 1997, he successfully passed the external aggregation contest. In 2012 and 2017 he received respectively the M.Sc and Ph.D in Automatic Signal Processing and Industrial Computing from HASSAN $1^{\text {st }}$ University - FST of Settat Morocco. In 2018, he joined the Hassan 2 University of Casablanca, Morocco. Currently, he is Research Professor in Laboratory of Structural Engineering, Intelligent Systems \& Electrical Energy at National High School of Arts and Crafts ENSAM, and Department of Electrical Engineering. His research interests include control strategies for Power Electronics Converters, Multilevel inverters, PV systems, AC machine Drives, renewable energy, SmartGrids, Power Quality and Power to X. He can be contacted at email: radouane.majdoul@univh2c.ma

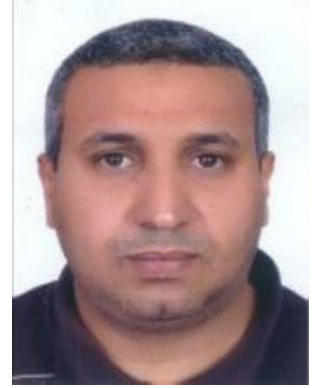

Abdelwahed Touati (iD 8S SC P was born in Casablanca, Morocco, in 1970. He received the Engineer degree in electrical Engineering from High Institute of Technical Education (ENSET) of Mohammedia in 1993. In 1999, he successfully passed the external aggregation contest. In 2012 he received the MASTER ATSII (Automatic Signal Processing and Industrial Computing) from HASSAN 1 University - FST of SETTAT Morocco. Currently, he is Research Professor in Laboratory of Structural Engineering, Intelligent Systems \& Electrical Energy at National High School of Arts and Crafts ENSAM, and Department of Electrical Engineering - Hassan II University Casablanca, Morocco. His research interests include control strategies for AC machine Drives, Wind renewable energy and Power Quality. He can be contacted at email: touati_2010@ hotmail.com

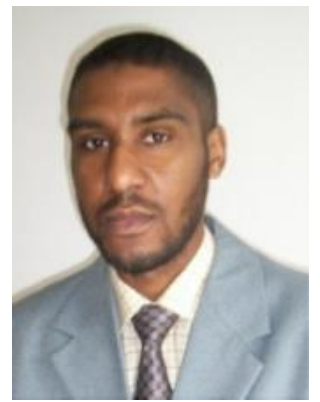

Abderrahmane Ouchatti (iD) IS SC P was born Morocco in 1972. He received the Engineer degree in electrical Engineering from High Institute of Technical Education (ENSET) of Rabat in 1994. Received the Aggregation in Electrical Engineering from ENSET, Rabat, in 2000. He received the M.Sc in Automatic, Signal Processing and Industrial Computing from HASSAN $1^{\text {st }}$ University - FST of Settat Morocco in 2011. He received in 2018, the Ph.D degree in Industrial electronics and electrical machines from Engineering Mohammadia high School of Rabat in Morocco. Currently he is Research Professor in Laboratory of Electrical Systems \& Control Engineering (ESCE) - Aïn Chock Science faculty of Casablanaca. His research interests include control strategies for AC machine Drives, renewable energy and Multilevel converters. He can be contacted at email: ouchatti_a@yahoo.fr 

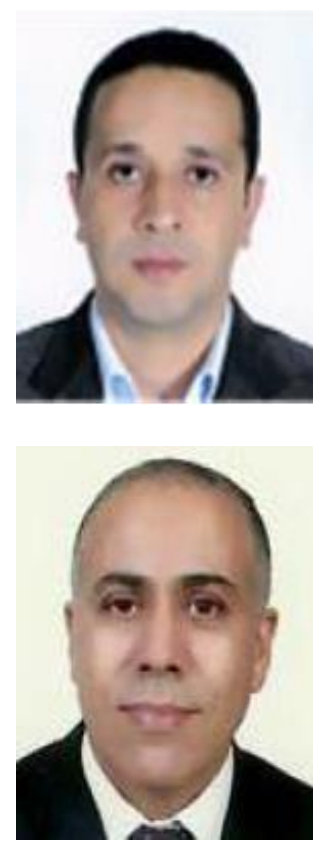

Abderrahim Taouni (D) 8d SC P was born in Morocco in 1974. He received the Engineer degree in electrical Engineering from High Institute of Technical Education (ENSET) of Mohammedia in 1997. Received the Aggregation in Electrical Engineering from the Ecole Normal Superior of Technical Education (ENSET), Rabat, in 2008. He received the Master degree in ATSII (Automatic, Signal Processing and Industrial Computing) from Faculty of Science and Technology Hassan I university SETTAT, Morocco in 2011. Currently he is Research Professor Laboratory of Electrical Systems \& Control Engineering (ESCE) - Aïn Chock Science faculty- Hassan II University Casablanca, Morocco. His research interests include control strategies for AC machine Drives, Power electronic converters, renewable energy and batteries. He can be contacted at email: taouni40@ hotmail.com

Elhassane Abdelmounim (D) $8 \mathrm{SC}$ ( P received his $\mathrm{PhD}$ in applied Spectral analysis from Limoges University at science and technical Faculty, France in 1994. In 1996, he joined, as Professor, applied physics department of science and technical faculty, Hassan $1^{\text {st }}$ University, Settat, Morocco. His current research interests include digital signal processing and machine learning. He is currently coordinator of a Bachelor of Science in electrical engineering and researcher in "ASTI" System Analysis and Information Technology Laboratory at science and technical faculty, Hassan 1st University, Settat, Morocco. He can be contacted at email: abdelmou@gmail.com 